\title{
Maternal hypercholesterolemia programs dyslipidemia in adult male mouse progeny
}

\author{
Joyce Mathew ${ }^{1, *}$, Sze-chi Huang1,*, Jerad H Dumolt ${ }^{1}$, Mulchand S Patel ${ }^{2}$ and Todd C Rideout ${ }^{1}$ \\ ${ }^{1}$ Department of Exercise and Nutrition Sciences, School of Public Health and Health Professions, University at \\ Buffalo, Buffalo, New York, USA and 'Department of Biochemistry, Jacobs School of Medicine and Biomedical \\ Sciences, University at Buffalo, Buffalo, New York, USA
}

Correspondence should be addressed to T C Rideout; Email: rideout@buffalo.edu

*(J Mathew and S Huang contributed equally to this work)

\begin{abstract}
As a collection of metabolic abnormalities including inflammation, insulin resistance, hypertension, hormone imbalance, and dyslipidemia, maternal obesity has been well-documented to program disease risk in adult offspring. Although hypercholesterolemia is strongly associated with obesity, less work has examined the programming influence of maternal hypercholesterolemia (MHC) independent of maternal obesity or high-fat feeding. This study was conducted to characterize how MHC per se impacts lipid metabolism in offspring. Female ( $n=6 /$ group) $\mathrm{C} 57 \mathrm{BL} / 6 \mathrm{~J}$ mice were randomly assigned to: (1.) a standard chow diet (Control, $\mathrm{CON}$ ) or (2.) the $\mathrm{CON}$ diet supplemented with exogenous cholesterol $(\mathrm{CH})(0.15 \%, w / w)$ throughout mating and the gestation and lactation periods. At weaning (postnatal day (PND) 21) and adulthood (PND 84), male offspring were characterized for blood lipid and lipoprotein profile and hepatic lipid endpoints, namely cholesterol and triglyceride (TG) accumulation, fatty acid profile, TG production, and mRNA expression of lipid-regulatory genes. Both newly weaned and adult offspring from $\mathrm{CH}$ mothers demonstrated increased very low-density lipoprotein (VLDL) particle number and size and hepatic TG and n-6 polyunsaturated fatty acid accumulation. Further, adult $\mathrm{CH}$ offspring exhibited reduced fatty acid synthase (Fasn) and increased diglyceride acyltransferase (Dgat1) mRNA expression. These programming effects appear to be independent of changes in hepatic TG production and postprandial lipid clearance. Study results suggest that MHC, independent of obesity or high-fat feeding, can induce early changes to serum VLDL distribution and hepatic lipid profile that persist into adulthood.

Reproduction (2020) $\mathbf{1 6 0} 1-10$
\end{abstract}

\section{Introduction}

An unfavorable in utero nutritional and/or metabolic state during pregnancy can adversely affect fetal development and predispose offspring to disease risk throughout life (Friedman 2018, Blin et al. 2020). Further still, diet and metabolic health factors of the mother after birth can alter the nutrient and bioactive nonnutritive components (e.g. hormones and inflammatory mediators) of maternal milk to influence the transmission of disease risk in newborns (Fields \& Demerath 2012, Isganaitis et al. 2019).

Given that an estimated $50 \%$ of pregnant women in the United States are overweight or obese (Davis 2020), concerns regarding the developmental origins of health and disease are heavily focused on maternal obesity. Offspring from obese pregnancies are predisposed to a wide range of metabolic complications as adults including obesity (Diaz et al. 2020), cardiovascular disease (Gaillard et al. 2016), and diabetes (Hussen et al. 2015). However, although obesity is often oversimplified at a population level through indices of excess body weight and adiposity (Neeland et al. 2018), it is nonetheless a complex disease state manifesting in multiple metabolic abnormalities including inflammation, insulin resistance, hypertension, adipose tissue dysfunction, and dyslipidemia, among others (Jung \& Choi 2014, Goossens 2017). Therefore, from a mechanistic perspective, the confounding of multiple obesity-associated metabolic adaptations during pregnancy make it difficult to discern the specific contribution of individual metabolic insults during early development to later-life disease risk. For instance, although maternal obesity is intricately linked to hypercholesterolemia with dysregulated hepatic cholesterol metabolism (Stahlberg et al. 1997, Haeusler et al. 2016), small, dense LDL particles (Kulanuwat et al. 2015), and low HDL-C, the effects of maternal hypercholesterolemia (MHC) during pregnancy per se on offspring development and disease risk have rarely been investigated independent of maternal obesity or high-fat feeding. Still, human studies have reported that 
excessive early exposure to cholesterol is associated with multiple adverse health outcomes including fecundity (Schisterman et al. 2014), pre-term delivery and low birth weight (Magnussen et al. 2011, Maymunah et al. 2014), increased childhood BMI and adiposity (Romejko-Wolniewicz et al. 2014, Daraki et al. 2015), increased blood lipids in the neonatal, adolescent, and adult periods (Morrison et al. 2013, Narverud et al. 2015, Mendelson et al. 2016), and fetal fatty streaks that develop faster in childhood (Napoli et al. 1999). Several reports suggest that familial hypercholesterolemic (FH) offspring with maternal inheritance and thus exposure to excessive intrauterine cholesterol have increased CVD risk compared with offspring who inherited $\mathrm{FH}$ from their father (van der Graaf et al. 2010, Versmissen et al. 2011). However, inconsistent results have also been reported (Tonstad et al. 2000, Narverud et al. 2015), suggesting that other influencing factors related to epigenetics (which is rarely studied) and postnatal environment and lifestyle are incompletely understood.

Although we have previously employed the apolipoprotein $\mathrm{E}$ deficient $\left(\mathrm{apo}^{-/-}\right)$mouse model to demonstrate that $\mathrm{MHC}$ can program hepatic fat accumulation in male offspring (Dumolt et al. $2019 a, b)$, this mouse is genetically predisposed to hypercholesterolemia and atherosclerosis, perhaps limiting the translational significance of this model. Therefore, the current study was conducted to examine if the hepatic programming effects of MHC per se, without the confounding influence of maternal obesity, high-fat feeding, or genetic predisposition, could be replicated in WT mice (C57BL6/J).

\section{Materials and methods}

\section{Animals and diets}

The animals used in this experiment were cared for in accordance with the guidelines established by the Institutional Animal Care and Use Committee (IACUC). All procedures were reviewed and approved by the Animal Care Committee at the University at Buffalo (protocol \#PTE16082N).

\section{Experiment 1}

This experiment was essentially a replication of our earlier work in apoE $\mathrm{E}^{-/-}$mice (Dumolt et al. 2019a) to characterize the blood and hepatic lipid phenotype in male offspring (both newly weaned and adults) exposed to cholesterol throughout the gestation and lactation periods, this time in C57BL/6 mice. Two-month-old female $(n=12)$ C57BL/6J dams (stock \#000664) were purchased from Jackson Laboratory and housed individually at the University at Buffalo in the Laboratory Animal Care Facility in a temperature-controlled room $\left(20^{\circ} \mathrm{C}\right)$ with free access to water. Mice were provided an acclimation period of 1 week to adjust to the new environment and research staff prior to initiation of experiments. Dams ( $n=6 /$ group) were randomly assigned to chow-based isocaloric diets: (1.) a standard chow diet (Control (CON), Teklad Global 19\% Protein Rodent Diet) or (2.) the CON diet supplemented with exogenous cholesterol (CH) $(0.15 \%$, w/w, CH, Teklad diet \#150003) (Table 1). Dams were fed their respective diets ad libitum throughout mating and the gestation and lactation periods. Female mice were timed-mated with $\mathrm{CON}$-fed male breeders by observing the presence of vaginal plugs or observation of spermatozoa in vaginal lavage. To maintain some consistency in exposure to the $\mathrm{CH}$ diet, females that did not become pregnant within 1 week were excluded from the study. Male breeders were exposed to the $\mathrm{CH}$ diet for the overnight breeding periods only, which averaged $\sim 5$ nights. Following parturition on postnatal day 0 (PND), the number of pups born and their weights were recorded. On PND 2, litters were randomly culled to six pups (irrespective of sex) per dam in order to minimize variability in pup growth influenced by litter size. In order to prevent pups from feeding on the experimental diet during lactation, food pellets were placed on raised platforms accessible only to dams and cages were changed daily to remove any diet waste. On PND 21, mothers and one male pup from each litter were killed for blood and liver phenotyping. An additional male pup was weaned onto the CON diet until adulthood (PND 84) for blood and liver lipid phenotyping.

\section{Experiment 2}

These experiments were conducted with a separate cohort of breeding female dams to characterize hepatic TG production (newly weaned and adult animals) and postprandial lipid clearance (adults only) in offspring exposed to excessive early cholesterol. Dams ( $n=6$ per CON and $\mathrm{CH}$ groups, respectively) underwent identical diet and breeding procedures as outlined previously. At weaning, two male pups per litter were weaned onto the CON diet until adulthood (PND 120) to characterize hepatic TG production and postprandial lipid clearance.

Table 1 Diet formulation.

\begin{tabular}{lcc}
\hline Macronutrients $(\%)^{\mathbf{1}}$ & $\mathbf{C O N}$ & $\mathbf{C H}$ \\
\hline Crude protein & 18.9 & 18.7 \\
Fat & 7.9 & 7.7 \\
Carbohydrate & 51.5 & 51.3 \\
Crude fiber & 2.6 & 2.6 \\
Ash & 5 & 5 \\
Cholesterol & - & 0.15 \\
Energy density (kcal/g) & 3.3 & 3.5 \\
\% kcal from: & & \\
$\quad$ Protein & 21.4 & 21.4 \\
$\quad$ Fat & 20.1 & 19.8 \\
$\quad$ Carbohydrate & 58.5 & 58.7 \\
\hline
\end{tabular}

${ }^{1}$ Ingredients (in descending order of inclusion) - Ground wheat, ground corn, corn gluten meal, wheat middlings, soybean oil, calcium carbonate, dicalcium phosphate, brewers dried yeast, L-lysine, iodized salt, magnesium oxide, choline chloride, DL-methionine, calcium propionate, L-tryptophan, vitamin E acetate, menadione sodium bisulfite complex (source of vitamin K activity), manganous oxide, ferrous sulfate, zinc oxide, niacin, calcium pantothenate, copper sulfate, pyridoxine hydrochloride, riboflavin, thiamin mononitrate, vitamin A acetate, calcium iodate, vitamin B12 supplement, folic acid, biotin, vitamin D3 supplement, and cobalt carbonate. 
The remaining littermates (four pups, irrespective of sex) were used to examine hepatic TG production at weaning.

Hepatic TG production was measured according to the procedures by (Millar et al. 2005). Following a 3-h fast, mice were placed under isoflurane anesthesia (3.5\%) for baseline tail vein blood collection $(\sim 25-50 \mu \mathrm{L})$ using a lancet and microcapillary tube. Mice were then given an intraperitoneal injection (1000 mg/kg or $5 \mu \mathrm{L} / \mathrm{g}$ body weight) of purified P-407, a lipase inhibitor, prepared as a $20 \%$ solution in physiological saline by cold-method incorporation (Palmer et al. 1998). Blood was then collected from the tail vein at 1,3 , and $6 \mathrm{~h}$ following injection for serum separation and TG analysis as described subsequently. Adult TG production studies were conducted in male mice only (one male pup/ litter, $n=6$ ). However, given the volume limitations associated with repeated tail vein collection in newly weaned pups, hepatic TG production studies at weaning were conducted with a mixture of male and female pups using one pup for each time point (four pups/litter).

Postprandial lipid clearance studies were conducted in adult male offspring (PND 84, one male pup/litter, $n=6$ ) following a 5 -h fast. Following baseline tail vein blood collection, mice were administered food grade olive oil with a feeding needle (21 gauge) at a dose of $10 \mu \mathrm{L} / \mathrm{g}$ body weight. At 1,2 , and $3 \mathrm{~h}$ post gavage, blood was collected through the tail vein for TG measurement as described subsequently.

\section{Blood lipid analyses}

Blood lipids and lipoprotein particle number and size were analyzed by NMR spectroscopy (Liposcience, Raleigh, NC) (Jeyarajah et al. 2006). Non-HDL cholesterol was calculated by subtracting $\mathrm{HDL}-\mathrm{C}$ from total cholesterol. Serum cholesterol panel, including TC, HDL-C, and LDL/VLDL-C, was measured through enzymatic assay (BioAssay Systems, Hayward, CA).

\section{Hepatic lipid analyses}

Hepatic cholesterol and fatty acid composition were analyzed using gas chromatography on a Shimadzu GC-17A gas chromatograph with a flame ionization detector using a SAC-5 capillary column $(30 \mathrm{~m} \times 0.25 \mathrm{~mm} \times 0.25 \mathrm{~mm}$, Supelco, Bellefonte, CA) according to our previously published procedures (Rideout et al. 2010, Carrier et al. 2014). Relative hepatic FA content was calculated by using individual FA peak area relative to the total area and expressed as the percentage of total FA. Frozen pulverized liver tissue (100 mg) was homogenized in $1 \mathrm{~mL}$ of aqueous 5\% NP-40 solution, heated at $90^{\circ} \mathrm{C}$ for $10 \mathrm{~min}$, and spun at top speed in a microcentrifuge for $2 \mathrm{~min}$ to obtain hepatic extracts for TG analyses (Zenbio, STG-1-NC) (Green \& Kehinde 1974).

\section{RNA preparation and real-time $R T$-PCR}

Total RNA was isolated from whole liver tissue using RNA extraction kit (RNeasy Mini Kit, Qiagen). RNA concentration and integrity were determined with spectrophotometry $(260 \mathrm{~nm})$ and agarose gel electrophoresis, respectively. RNA preparation and real-time RT-PCR were completed through the one-step
QuantiFast SYBR Green RT-PCR kit (Qiagen Inc.) using a Biorad CFX96 Touch real time PCR. Gene expression was determined through the 2(-delta delta Ct) method (Pfaffl 2001). Sequences of sense and antisense primers for target and housekeeping genes were based on previously published reports: $\beta$-actin (Actb) (Zhou et al. 2012): 5'GACAGGATGCAGAAGGAG-ATT3' (forward), 5'TGATCCACATCTGCTGGAAGG3' (reverse); acetyl-coA carboxylase (Acaca) (Zhou et al. 2008): 5'CAACCACTACGGCATGACTCA3' (forward), 5' CGCAGAAGCAGCCCATTACTT 3' (reverse); fatty acid synthase (Fasn) (Graner et al. 2004): 5' CСТCAGTCCTGTTATCACCCGA 3' (forward), 5' GCTGAATACGACCACGCACTA 3' (reverse); sterol regulatory element binding protein 1c (Srebf1) (Sim et al. 2014): 5' TGG-AGACATCGCAAACAAG 3' (forward), 5' GGTAGACAACAGCCGCATC3' (reverse);Apolipoprotein B-100 (Apob100) (Kanuri et al. 2011): 5' TCACCATTTGCCCTCAACCT 3' (forward), 5' CAGGTCAACATCGGCAATCA 3' (reverse); diglyceride acyltransferase (Dgat1) (Zhou et al. 2008): 5' CAGATGGGGCTGCTGCTACAT 3' (forward), 5' GGCGGCACC-ACAGATTGACAT 3' (reverse); and microsomal triglyceride transfer protein (Mttp) (Vrins et al. 2013): 5' TCAAGAGAGGCTTGGCTAGCTT 3' (forward), 5' GGCCTGGTAGGTCACT-TTACA-ATC 3' (reverse).

\section{Statistical analyses}

Based on our previous studies examining the impact of maternal cholesterol during gestation and lactation (Rideout et al. 2015, Liu et al. 2016), we estimated that we would require a sample size of six mothers/group for our primary endpoint of hepatic cholesterol (effect size, 1.32; power, 0.90; $P<0.05$ ). Litters from each dam were considered as a single observation ( $n=6$ dams per treatment group). Data were checked for normality using the Shapiro-Wilk test and are presented as means \pm S.E. For the hepatic TG production and lipid clearance studies, the area under the serum concentration vs time curve was calculated using the linear trapezoidal rule. Data were analyzed with a general linear model ANOVA using with SPSS 16 for Mac (SPSS Inc). Differences were considered significant at $P<0.05$.

\section{Results}

\section{Maternal phenotype}

Maternal body weight at baseline and at end of the lactation period did not differ $(P>0.05)$ between the two groups throughout the study period (Table 2). Further, gestational weight gains $(P>0.05)$ were similar between dams from each treatment group (Table 2). Although both groups of dams displayed nearly identical baseline serum cholesterol, $\mathrm{CH}$ dams demonstrated an increase in $(P<0.05)$ serum TC $(+30 \%)$ compared with CON dams (Table 2) by gestation week 1 . By week 2 of gestation, both groups had similar $(P>0.05)$ cholesterol concentrations that were below that of baseline. By the end of lactation, TC was significantly $(P<0.05)$ higher in hypercholesterolemic dams $(+38 \%$ compared with CON) (Table 2). However, LDL/VLDL-C 
Table 2 Maternal phenotype including weight, gestational serum cholesterol and post-lactation serum lipids, and hepatic cholesterol in control $(\mathrm{CON})$ and hypercholesterolemic $(\mathrm{CH})$ dams.

\begin{tabular}{lcc}
\hline Endpoint & CON & CH \\
\hline Maternal weight & & \\
$\quad$ Baseline (g) & $21.5 \pm 1.1$ & $21.8 \pm 0.8$ \\
$\quad$ Gestational weight gain $(\mathrm{g})$ & $16.0 \pm 0.9$ & $16.1 \pm 0.8$ \\
$\quad$ End of lactation weight & $28.7 \pm 0.65$ & $30.0 \pm 1.3$ \\
Gestational serum cholesterol (mg/dL) & & \\
$\quad$ Baseline & $57.7 \pm 2.0$ & $55.0 \pm 2.8$ \\
$\quad$ Week 1 & $67.0 \pm 3.5$ & $87.5 \pm 3.7^{*}$ \\
$\quad$ Week 2 & $35.8 \pm 4.6$ & $43.9 \pm 4.8$ \\
Serum lipids (mg/dL, post-lactation) & & \\
TC & $150.4 \pm 7.5$ & $208.2 \pm 25.5^{*}$ \\
$\quad$ LDL/VLDL-C & $24.0 \pm 1.8$ & $25.6 \pm 1.7$ \\
$\quad$ HDL-C & $140.4 \pm 14.0$ & $156.1 \pm 19.2$ \\
Hepatic lipids ( $\mu \mathrm{mol} / \mathrm{g}$, post-lactation) & & \\
$\quad$ Cholesterol & $10.1 \pm 0.6$ & $25.1 \pm 1.2^{*}$ \\
\hline
\end{tabular}

Data represent mean \pm S.E., $n=6$ per group; groups with an asterisk $\left.{ }^{*}\right)$ are significantly different $(P \leq 0.05)$. Maternal post-lactation measures were taken at the end of lactation to coincide with postnatal day 21 offspring outcomes.

and HDL-C levels in dams by the end of lactation were not significantly different $(P>0.05)$ between treatment groups. Maternal hepatic cholesterol concentration post-lactation was higher $(+147 \%, P<0.05)$ in the $\mathrm{CH}$ dams compared with CON dams (Table 2).

\section{Offspring phenotype}

No difference $(P>0.05)$ was observed in litter birth weights $(9.47 \pm 0.67 \mathrm{~g}$ for $\mathrm{CON}$ vs $9.48 \pm 0.52 \mathrm{~g}$ for $\mathrm{CH})$, litter birth size $(7.83 \pm 0.60$ pups for CON vs $7.33 \pm 0.56$ for $\mathrm{CH}$ ), and sex ratio (53 $\pm 5 \%$ male for CON vs $58 \pm 8 \%$ male for $\mathrm{CH}$ after culling). Further, litter growth during lactation and postnatal growth of $\mathrm{CON}$-fed male pups was similar $(P>0.05)$ between offspring from $C O N$ and $\mathrm{CH}$ dams (Fig. 1).

Serum lipid concentrations, including TC, LDL-C, HDL-C, non-HDL-C, and TG, were not different $(P>0.05)$ in newly weaned pups from $\mathrm{CON}$ and $\mathrm{CH}$ dams (Fig. 2A). Adult offspring born to $\mathrm{CH}$ dams demonstrated higher serum TG $(+19 \%, P<0.05)$ concentrations compared with offspring from CON dams (Fig. 2B); however, no other changes in serum lipids were noted. Total VLDL particle number was higher $(P<0.05)$ in both newly weaned $(+145 \%)$ and adult $(+29 \%)$ offspring from $\mathrm{CH}$ vs $\mathrm{CON}$ dams (Fig. $3 \mathrm{~A}$ and $\mathrm{C}$ ). However, there was no difference $(P>0.05)$ in total LDL or HDL particle number in newly weaned or adult offspring between the two groups. In addition, VLDL particle size was increased $(P<0.05)$ in both newly weaned $(+37 \%)$ and adult (+65\%) offspring from $\mathrm{CH}$ vs CON dams (Fig. $3 \mathrm{~B}$ and $\mathrm{D})$. LDL and HDL size did not differ $(P>0.05)$ between both groups at any stage of development.

Liver weights (mg, normalized to body weight) did not differ $(P>0.05)$ between the chow and $\mathrm{CH}$ groups
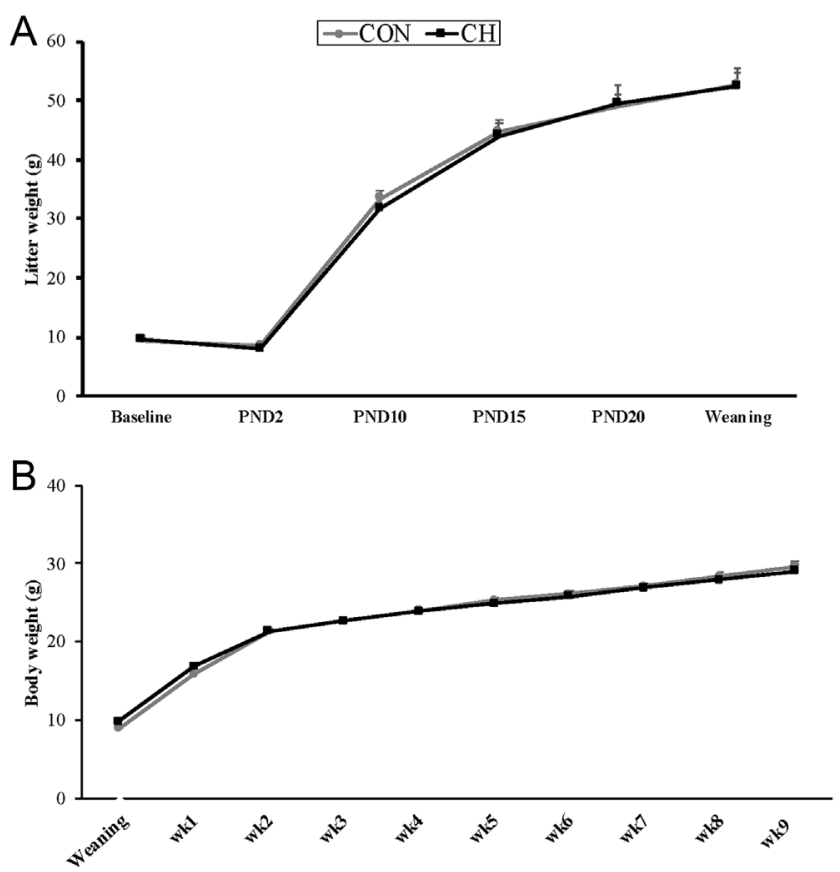

Figure 1 Litter growth (g) during lactation (A) and growth of CON-fed male offspring in the postnatal period. Data are means \pm S.E.; $n=6$ mothers/group.

at weaning $(33.3 \pm 1.3$ for $\mathrm{CON}$ vs $33.7 \pm 1.2$ for $\mathrm{CH})$ or adulthood $(50.6 \pm 2.3$ for $\mathrm{CON}$ vs $46.5 \pm 1.9$ for $\mathrm{CH})$. Newly weaned offspring born to $\mathrm{CH}$ dams demonstrated higher $(P<0.05)$ hepatic cholesterol concentration $(+34 \%)$ compared with CON dams (Fig. 4A). However, this difference did not persist into adulthood (Fig. 4C). Both newly weaned and adult offspring born to $\mathrm{CH}$ dams demonstrated elevated hepatic TG compared with CON dams $(+153 \%$ and $+475 \%$, respectively, Fig. 4B and D).

Changes in hepatic TG were associated with altered hepatic fatty acid profile in both newly weaned and adult offspring (Fig. 5). Newly weaned pups from HC dams had lower $(P<0.05)$ total monounsaturated fatty acid (MUFA) and higher $(P<0.05)$ polyunsaturated fatty acid (PUFA) concentration, mainly due to an increase in n-6 PUFA species (Fig. 5A). Adult offspring from HC dams demonstrated higher $(P<0.05)$ n-6 PUFA and a lower $(P<0.05)$ palmitic to linoleic fatty acid ratio (16:0/18:2n-6) (Fig. 5B).

Although no group differences were observed in hepatic mRNA targets in newly weaned offspring, changes in hepatic lipid profile were associated with a reduction $(P<0.05)$ in Fasn $(\sim 0.5$ fold of CON $)$ and increase in Dgat1 ( $\sim 1.5$ fold of CON) mRNA expression in adult offspring from $\mathrm{CH}$ vs $\mathrm{CON}$ dams (Table 3).

Serum TG concentration demonstrated a rapid increase $1 \mathrm{~h}$ following administration of P407 and did not return to baseline by the 6-h timepoint (Fig. 6). However, the observed absolute rise in plasma TG and 

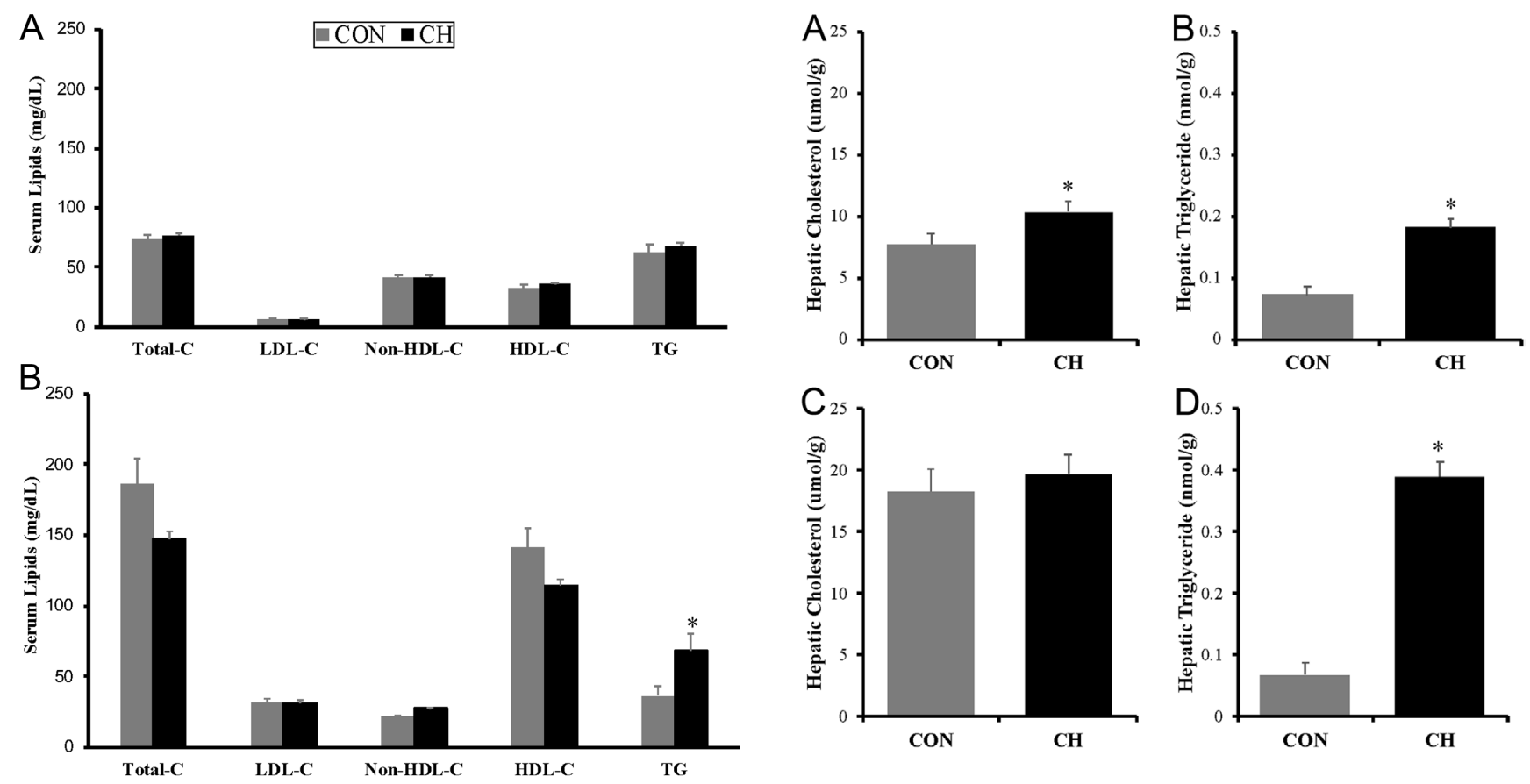

Figure 2 Serum lipids in newly weaned pups (A) and adult CON-fed offspring (B) born to control (Con) or hypercholesterolemic $(\mathrm{CH})$ dams. Data are means \pm S.E.; $n=6$ mothers/group; ${ }^{*} P<0.05 . n=6$ mothers/groups; $* P<0.05$.

AUC for TG did not differ $(P>0.05)$ in newly weaned (male and female pups, Fig. 6A) or adult male offspring (Fig. 6B) from $\mathrm{CH}$ vs $\mathrm{CON}$ dams.

Serum TG concentration following an oral fat tolerance test in adult male offspring is presented in Fig. 7. The TG concentration increased from 0 to $3 \mathrm{~h}$ post gavage in
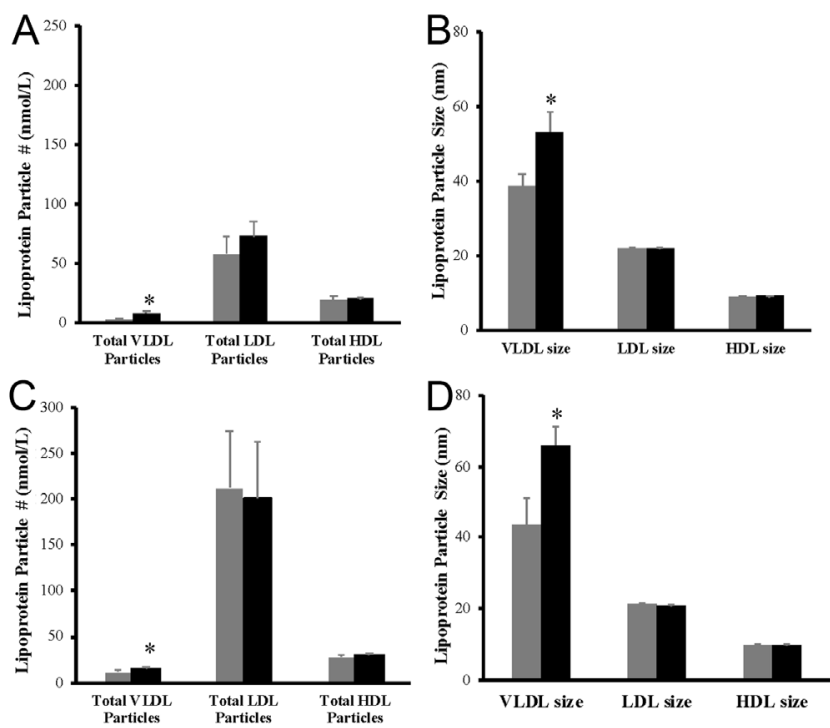

Figure 3 Lipoprotein particle number and size in newly weaned (A and $\mathrm{B}$ ) and adult ( $\mathrm{C}$ and $\mathrm{D}$ ) offspring from control (Con) and hypercholesterolemic $(\mathrm{CH})$. Data are mean \pm S.E.; $n=6$ mothers/group; $* P<0.05$.
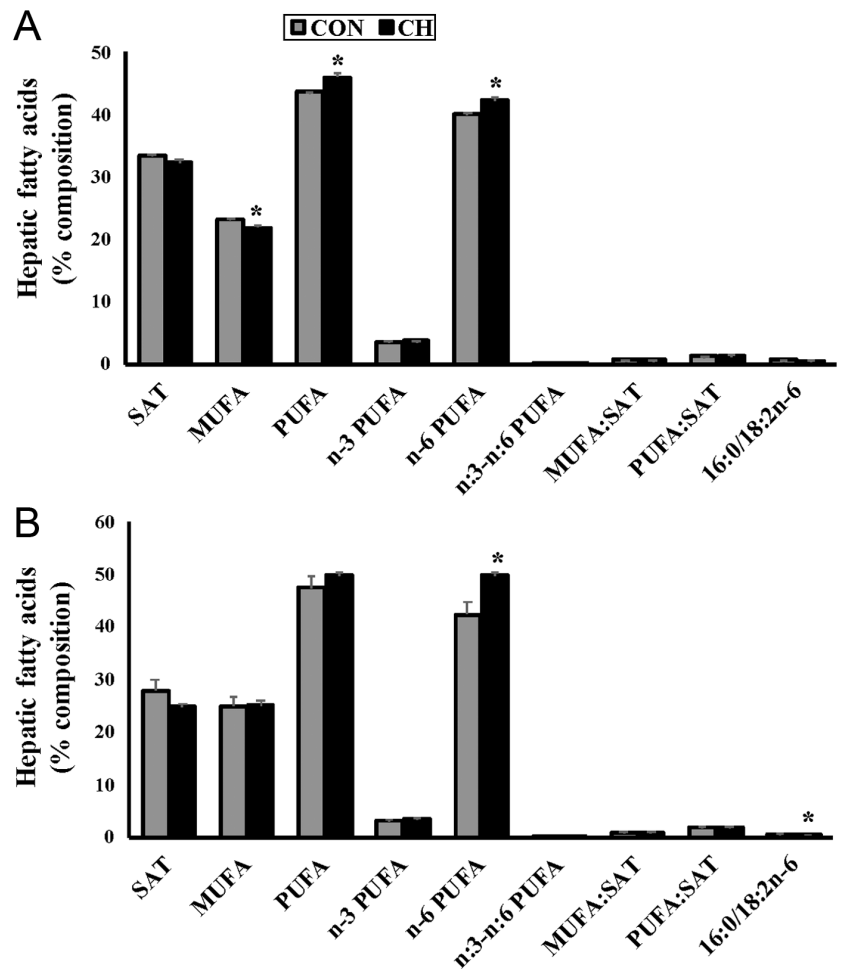

Figure 5 Hepatic fatty acid profile in newly weaned pups (postnatal day 21) (A) and adult offspring (postnatal day 84) (B) from control $(\mathrm{CON})$ and hypercholesterolemic $(\mathrm{CH})$ dams. Groups with an asterisk $\left.{ }^{*}\right)$ are significantly different $(n=6, P<0.05)$. 
Table 3 Hepatic mRNA expression of lipid regulatory targets in newly weaned pups (postnatal day 21) and adult (postnatal day 84) offspring from control $(\mathrm{CON})$ and hypercholesterolemic $(\mathrm{CH})$ dams.

\begin{tabular}{lcc}
\hline Gene & CON & CH \\
\hline Postnatal day 21 & & \\
Acaca & $1.0 \pm 0.10$ & $1.01 \pm 0.14$ \\
Fasn & $1.0 \pm 0.22$ & $1.13 \pm 0.29$ \\
Srebf1 & $1.0 \pm 0.35$ & $0.57 \pm 0.04$ \\
Apob100 & $1.0 \pm 0.21$ & $1.05 \pm 0.12$ \\
Dgat1 & $1.0 \pm 0.14$ & $0.98 \pm 0.17$ \\
Mttp & $1.0 \pm 0.15$ & $1.40 \pm 0.15$ \\
Postnatal day 84 & $1.0 \pm 0.12$ & \\
Acaca & $1.0 \pm 0.19$ & $1.01 \pm 0.15$ \\
Fasn & $1.0 \pm 0.29$ & $0.54 \pm 0.11 *$ \\
Srebf1 & $1.0 \pm 0.13$ & $0.68 \pm 0.08$ \\
Apob100 & $1.0 \pm 0.10$ & $1.18 \pm 0.14$ \\
Dgat1 & $1.0 \pm 0.13$ & $1.52 \pm 0.13^{*}$ \\
Mttp & & $1.39 \pm 0.19$ \\
\hline
\end{tabular}

Data represent mean \pm S.E., $n=6$ per group; groups with an asterisk $\left(^{*}\right)$ are significantly different $(P \leq 0.05)$.

both groups; however, no difference $(P>0.05)$ between offspring from $\mathrm{CON}$ and $\mathrm{CH}$ dams was observed.

\section{Discussion}

Results from this study suggest that $\mathrm{MCH}$, independent of obesity or high-fat feeding, can program early adaptations in lipid metabolism that ultimately lead to dyslipidemia in adult male progeny. Specifically, adult
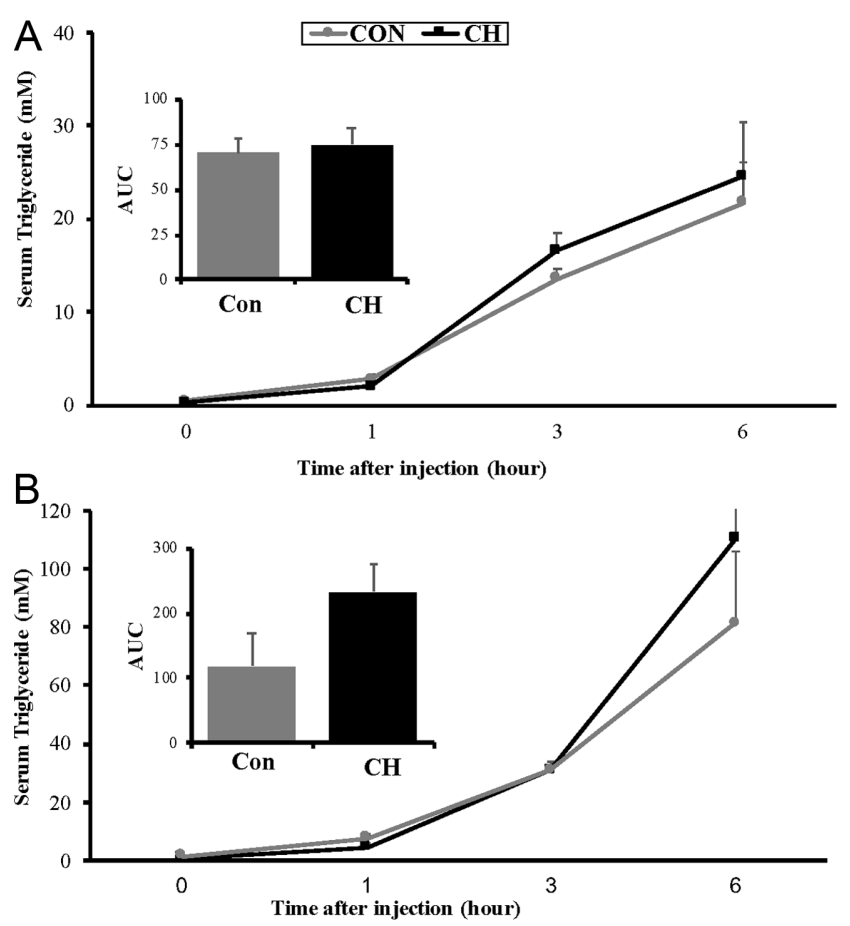

Figure 6 Time course of serum triglycerides following administration of P-407 in newly weaned (A) and adult (B) offspring born to control (Con) and hypercholesterolemic $(\mathrm{CH})$ dams. Inserts show area under curve analysis of data. Data are mean \pm S.E.; $n=6$ mothers/group.

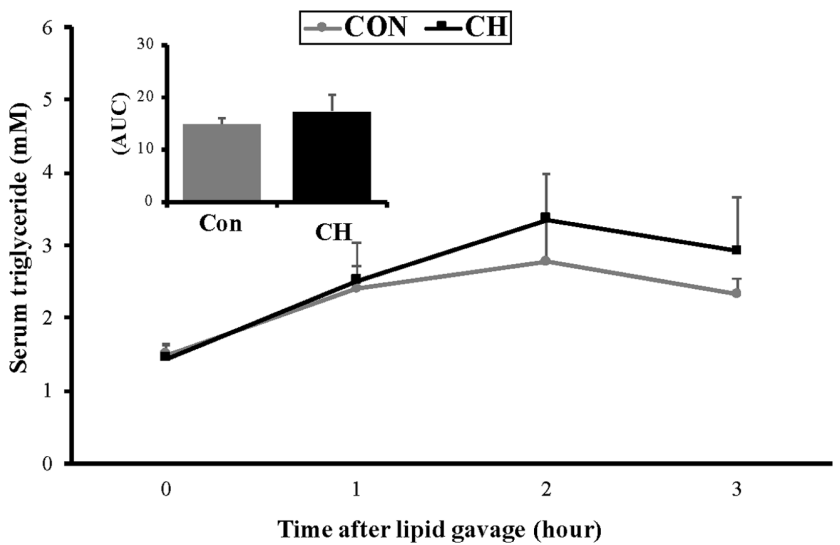

Figure 7 Plasma triglycerides following an oral fat tolerance test in adult offspring born to control (Con) and hypercholesterolemic $(\mathrm{CH})$ dams. Insert show area under curve analysis of data. Data are mean \pm S.E.; $n=6$ mothers/group.

male offspring from hypercholesterolemic mothers exhibited: (1.) hypertriglyceridemia and increased VLDL particle number and size; (2.) TG accumulation and modified fatty acid profile in the liver; and (3.) differential hepatic gene profile including reduced Fasn and increased Dgat1 mRNA expression. Our findings further suggest that changes in hepatic lipid content are not associated with alterations in hepatic TG production or postprandial lipid clearance.

The observed increase in the number of VLDL particles in $\mathrm{CH}$ offspring (both newly weaned and adults) is noteworthy for several reasons. First, an increase in the number of VLDL particles may have potential cardiovascular implications as they are the direct precursors of LDL, the main causative lipid fraction in atherosclerosis (Ference et al. 2017). However, we observed no change in the LDL particle profile, which is in contrast to our previous examination of $\mathrm{MHC}$ in apoE $\mathrm{E}^{-/}$mice in which newly weaned offspring from hypercholesterolemic mothers exhibited increased VLDL and LDL particle numbers (Juritsch et al. 2017). Interestingly, unlike LDL receptor-deficient mice, it has been reported that apoE ${ }^{--}$mice do not demonstrate increased LDL particles, rather accumulation of cholesterol-enriched chylomicron remnants and VLDL remnants (Maeda 2011). These results highlight important model differences and the need to study the effects of MHC in a human population.

Second, previous research has implicated TG-rich lipoproteins including VLDL in atherosclerosis (Oorni et al. 2019). A small, dense LDL subfraction is thought to contribute substantially to atherosclerotic plaque development; however, a number of studies suggest that VLDL remnants may also facilitate atherosclerosis progression (Freedman et al. 1998, Colhoun et al. 2002, Prenner et al. 2014). Although the large size of VLDL particles may limit their entry into the arterial intima, VLDL remodeling by cholesterol-ester transport protein 
(CETP)-mediated TG transfer to HDL and lipolysis through lipoprotein lipase results in smaller VLDL particles that can be taken up and retained within the arterial wall (Vasile et al. 1989, Rutledge et al. 2000). Interestingly, although offspring from $\mathrm{CH}$ mothers had more VLDL particles, they were also larger in size, suggesting potential protection against arterial infiltration given their lower rate of arterial entrance (German et al. 2006). However, similar to LDL particles, larger VLDL particles may enter the arterial intima through leaky paracellular junctions as a result of endothelial dysfunction and associated vascular permeability induced by dyslipidemia (Magalhaes et al. 2016, Oorni et al. 2019).

The mechanisms underlying hypertriglyceridemia and associated VLDL profile changes in $\mathrm{CH}$ offspring are not entirely clear, although potential adaptations to hepatic lipid balance and/or peripheral lipoprotein metabolism are likely involved. As to the former, cholesterol-exposed offspring exhibited increased hepatic cholesterol (newly weaned only) and TG (newly weaned and adult). Furthermore, we observed increased total PUFA (newly weaned) and n-6 PUFA in $\mathrm{CH}$ offspring (both newly weaned and adults), which supports previous work reporting higher total PUFA content and $n-6$ fatty acids in NAFLD patients compared with healthy controls (Puri et al. 2007). The lower Fasn mRNA expression and reduced 16:0/18:2 ratio (an indirect marker of de novo lipogenesis (Hudgins et al. 1996)) in adult $\mathrm{CH}$ offspring could reflect a protective response to safeguard against excessive lipid deposition. In support of this theory, previous work has reported reductions in hepatic cholesterol synthesis (both HMG-CoAr mRNA expression (Tsuduki et al. 2016) and activity (Montoudis et al. 2003)) and FAS protein abundance (MarseilleTremblay et al. 2007) in response to excessive early cholesterol exposure. Precisely why MHC would lead to increased hepatic lipid synthesis in the first place has not been directly investigated; however, it is possible that excessive maternal-fetal cholesterol transfer could activate lipogenesis through an LXR-mediated pathway (Olkkonen et al. 2012). Indeed, the increase in hepatic DGAT expression in cholesterol-exposed adult offspring may support this theory and underscore a metabolic explanation for the observed hypertriglyceridemia. Previous work has reported increased levels of DGAT1 mRNA in human livers with NAFLD (Kohjima et al. 2007), supporting a direct role of DGAT activity in the pathogenesis of the disease. Hepatic DGAT1 expression has also been shown to be important in VLDL synthesis and secretion (Yamazaki et al. 2005), suggesting that, perhaps, increased Dgat1 expression in adult $\mathrm{CH}$ offspring may reflect enhanced VLDL-TG packaging as a means to protect against lipotoxicity. However, we observed no change in the mRNA expression of other VLDL synthesis targets (Apob100, Mttp) and no difference in hepatic TG production between the two groups. Although P-407 is widely used to measure hepatic TG production, it is not a direct measure of VLDL secretion and therefore we cannot rule out changes in VLDL secretion to the observed cholesterol-exposed phenotype.

Alternatively, adaptations in peripheral VLDL metabolism, including tissue lipolysis and/or clearance, may also account for the different VLDL profile between control and cholesterol-exposed offspring. However, we did not observe any treatment effect on postprandial lipid clearance, suggesting that early cholesterol exposure did not affect TG tissue uptake, at least in the postprandial period. However, we did not directly measure that VLDL lipolysis and chylomicrons would be the main carrier of TG in the postprandial period, perhaps diluting our ability to detect subtle changes in TG that are part of the VLDL fraction.

This study has several limitations with respect to design and translational application. First, although females were mated with CON-fed males, male breeding partners did have access to the $\mathrm{CH}$-enriched diet during overnight breeding sessions and there is increasing emphasis on paternal factors prior to conception and during sperm development that may be involved in malprogramming of offspring development. Second, our experiments were limited to male offspring, which may have divergent responses to their female counterparts. On this point, given the limitation of sequential blood collection in newly weaned animals, hepatic TG production studies at weaning were done with a mixture of male and female pups. Although the male:female ratio between litters was similar, we cannot rule out potential contribution of sex effects or inter-animal variation in the responses observed, even if offspring were from the same litter. Third, we chose to examine cholesterol exposure throughout both the gestation and lactation periods, as it may be more translatable to the human condition; however, it did not allow us to account for potential period-specific malprogramming effects of excessive cholesterol exposure. Regarding translation, we used the C57BL/6J mouse model, as it is susceptible to diet-induced obesity, hypercholesterolemia, and NAFLD (Anstee \& Goldin 2006, Chu et al. 2017). Although these mice are often used to model human lipid metabolism, there are well-documented differences including a larger fraction of cholesterol carried in HDL in mice vs humans (Camus et al. 1983). The cholesterol supplemented diet was used, as previous work has shown that this level of dietary incorporation $(0.15 \%)$ results in hypercholesterolemia in rodent models; however, it is unknown how the maternal cholesterol response observed mimics the human trajectory of cholesterol and lipoprotein fractions during pregnancy. Further, although the chow-based diet allowed us to examine hypercholesterolemia without the confounding effects of dietary fat or maternal obesity, its translational value may be limited as it is essentially a plant-based 
diet with a variety of bioactive compounds and a high level of dietary fiber.

In summary, results of this study suggest that MHC, independent of obesity or high-fat feeding, can induce early changes to the serum VLDL profile (increased particle number and size) and hepatic TG deposition and FA profile that persist into adulthood. Further, these changes were evident in the absence of a potential exacerbating effect of a high-fat or cholesterol diet in the postnatal period.

\section{Declaration of interest}

The authors declare that there is no conflict of interest that could be perceived as prejudicing the impartiality of the research reported.

\section{Funding}

This research was supported by a KO1 grant (1 K01 AT00782601A1) from the National Center for Complementary and Integrative Health $(\mathrm{NCClH})$ and a $\mathrm{KO} 1$ supplement from $\mathrm{NCClH}$ and the Office of Dietary Supplements (3K01AT007826-03S1) (to T C R).

\section{Author contribution statement}

J $M, S H$, and $\mathrm{H} H \mathrm{D}$ assisted with the animal studies. J $M$ and $\mathrm{S} \mathrm{H}$ conducted the lab analysis. J M, S H, J H D, M S P, and $\mathrm{T}$ C R interpreted the data and collaborated in writing and revising the manuscript. All authors read and approved the final manuscript.

\section{Acknowledgements}

The authors would like to thank the staff of the Laboratory Animal Facility at the University at Buffalo for their assistance in completing this work.

\section{References}

Anstee QM \& Goldin RD 2006 Mouse models in non-alcoholic fatty liver disease and steatohepatitis research. International Journal of Experimental Pathology 87 1-16. (https://doi.org/10.1111/j.0959-9673.2006.00465.x)

Blin G, Liand M, Mauduit C, Chehade H, Benahmed M, Simeoni U \& Siddeek B 2020 Maternal exposure to high-fat diet induces long-term derepressive chromatin marks in the heart. Nutrients 12 E181. (https:// doi.org/10.3390/nu12010181)

Camus MC, Chapman MJ, Forgez P \& Laplaud PM 1983 Distribution and characterization of the serum lipoproteins and apoproteins in the mouse, Mus musculus. Journal of Lipid Research 24 1210-1228.

Carrier B, Wen S, Zigouras S, Browne RW, Li Z, Patel MS, Williamson DL \& Rideout TC 2014 Alpha-lipoic acid reduces LDL-particle number and PCSK9 concentrations in high-fat fed obese Zucker rats. PLOS ONE 9 e90863. (https://doi.org/10.1371/journal.pone.0090863)

Chu DT, Malinowska E, Jura M \& Kozak LP 2017 C57BL/6J mice as a polygenic developmental model of diet-induced obesity. Physiological Reports 5 e13093. (https://doi.org/10.14814/phy2.13093)

Colhoun HM, Thomason MJ, Mackness MI, Maton SM, Betteridge DJ, Durrington PN, Hitman GA, Neil HA, fuller JH \& Collaborative
AtoRvastatin Diabetes Study (CARDS) 2002 Design of the Collaborative AtoRvastatin Diabetes Study (CARDS) in patients with type 2 diabetes. Diabetic Medicine 19 201-211. (https://doi.org/10.1046/j.14645491.2002.00643.x)

Daraki V, Georgiou V, Papavasiliou S, Chalkiadaki G, Karahaliou M, Koinaki S, Sarri K, Vassilaki M, Kogevinas M \& Chatzi L 2015 Metabolic profile in early pregnancy is associated with offspring adiposity at 4 years of age: the rhea pregnancy cohort Crete, Greece. PLoS ONE 10 e0126327. (https://doi.org/10.1371/journal.pone.0126327)

Davis AM 2020 Collateral damage: maternal obesity during pregnancy continues to rise. Obstetrical and Gynecological Survey 75 39-49. (https://doi.org/10.1097/OGX.0000000000000734)

Diaz EC, Cleves MA, Dicarlo M, Sobik SR, Ruebel ML, Thakali KM, Sims CR, Dajani NK, Krukowski RA, Borsheim E et al. 2020 Parental adiposity differentially associates with newborn body composition. Pediatric Obesity 15 e12596. (https://doi.org/10.1111/ijpo.12596)

Dumolt JH, Browne RW, Patel MS \& Rideout TC 2019a Malprogramming of hepatic lipid metabolism due to excessive early cholesterol exposure in adult progeny. Molecular Nutrition and Food Research 63 e1800563. (https://doi.org/10.1002/mnfr.201800563)

Dumolt JH, Ma M, Mathew J, Patel MS \& Rideout TC $2019 \mathrm{~b}$ Gestational hypercholesterolemia alters fetal hepatic lipid metabolism and microRNA expression in Apo-E-deficient mice. American Journal of Physiology: Endocrinology and Metabolism 317 E831-E838. (https://doi. org/10.1152/ajpendo.00138.2019)

Ference BA, Ginsberg HN, Graham I, Ray KK, Packard CJ, Bruckert E, Hegele RA, Krauss RM, Raal FJ, Schunkert H et al. 2017 Low-density lipoproteins cause atherosclerotic cardiovascular disease. 1. Evidence from genetic, epidemiologic, and clinical studies. A consensus statement from the European Atherosclerosis Society Consensus Panel. European Heart Journal 38 2459-2472. (https://doi.org/10.1093/eurheartj/ehx144)

Fields DA \& Demerath EW 2012 Relationship of insulin, glucose, leptin, IL-6 and TNF-alpha in human breast milk with infant growth and body composition. Pediatric Obesity 7 304-312. (https://doi.org/10.1111/ j.2047-6310.2012.00059.x)

Freedman DS, Otvos JD, Jeyarajah EJ, Barboriak JJ, Anderson AJ \& Walker JA 1998 Relation of lipoprotein subclasses as measured by proton nuclear magnetic resonance spectroscopy to coronary artery disease. Arteriosclerosis, Thrombosis, and Vascular Biology 18 1046-1053. (https://doi.org/10.1161/01.atv.18.7.1046)

Friedman JE 2018 Developmental programming of obesity and diabetes in mouse, monkey, and man in 2018: where are we headed? Diabetes 67 2137-2151. (https://doi.org/10.2337/dbi17-0011)

Gaillard R, Welten M, Oddy WH, Beilin LJ, Mori TA, Jaddoe VW \& Huang RC 2016 Associations of maternal prepregnancy body mass index and gestational weight gain with cardio-metabolic risk factors in adolescent offspring: a prospective cohort study. BJOG 123 207-216. (https://doi.org/10.1111/1471-0528.13700)

German JB, Smilowitz JT \& Zivkovic AM 2006 Lipoproteins: when size really matters. Current Opinion in Colloid and Interface Science 11 171-183. (https://doi.org/10.1016/j.cocis.2005.11.006)

Goossens GH 2017 The metabolic phenotype in obesity: fat mass, body fat distribution, and adipose tissue function. Obesity Facts 10 207-215. (https://doi.org/10.1159/000471488)

Graner E, Tang D, Rossi S, Baron A, Migita T, Weinstein LJ, Lechpammer M, Huesken D, Zimmerman J, Signoretti S et al. 2004 The isopeptidase USP2a regulates the stability of fatty acid synthase in prostate cancer. Cancer Cell 5 253-261. (https://doi.org/10.1016/ s1535-6108(04)00055-8)

Green H \& Kehinde O 1974 Sublines of mouse 3T3 cells that accumulate lipid. Cell 1 113-116. (https://doi.org/10.1016/0092-8674(74)90126-3)

Haeusler RA, Camastra S, Nannipieri M, Astiarraga B, Castro-Perez J, Xie D, Wang L, Chakravarthy M \& Ferrannini E 2016 Increased bile acid synthesis and impaired bile acid transport in human obesity. Journal of Clinical Endocrinology and Metabolism 101 1935-1944. (https://doi. org/10.1210/jc.2015-2583)

Hudgins LC, Hellerstein M, Seidman C, Neese R, Diakun J \& Hirsch J 1996 Human fatty acid synthesis is stimulated by a eucaloric low fat, high carbohydrate diet. Journal of Clinical Investigation 97 2081-2091. (https://doi.org/10.1172/JCI118645)

Hussen HI, Persson M \& Moradi T 2015 Maternal overweight and obesity are associated with increased risk of type 1 diabetes in offspring of 
parents without diabetes regardless of ethnicity. Diabetologia $\mathbf{5 8}$ 1464-1473. (https://doi.org/10.1007/s00125-015-3580-1)

Isganaitis E, Venditti S, Matthews TJ, Lerin C, Demerath EW \& Fields DA 2019 Maternal obesity and the human milk metabolome: associations with infant body composition and postnatal weight gain. American Journal of Clinical Nutrition 110 111-120. (https://doi.org/10.1093/ajcn/ nqy334)

Jeyarajah EJ, Cromwell WC \& Otvos JD 2006 Lipoprotein particle analysis by nuclear magnetic resonance spectroscopy. Clinics in Laboratory Medicine 26 847-870. (https://doi.org/10.1016/j.cll.2006.07.006)

Jung UJ \& Choi MS 2014 Obesity and its metabolic complications: the role of adipokines and the relationship between obesity, inflammation, insulin resistance, dyslipidemia and nonalcoholic fatty liver disease. International Journal of Molecular Sciences 15 6184-6223. (https://doi. org/10.3390/ijms15046184)

Juritsch A, Tsai YT, Patel MS \& Rideout TC 2017 Transcriptional control of enterohepatic lipid regulatory targets in response to early cholesterol and phytosterol exposure in apoE(-/-) mice. BMC Research Notes 10 529. (https://doi.org/10.1186/s13104-017-2859-3)

Kanuri G, Spruss A, Wagenerberger S, Bischoff SC \& Bergheim I 2011 Fructose-induced steatosis in mice: role of plasminogen activator inhibitor-1, microsomal triglyceride transfer protein and NKT cells. Laboratory Investigation 91 885-895. (https://doi.org/10.1038/ labinvest.2011.44)

Kohjima M, Enjoji M, Higuchi N, Kato M, Kotoh K, Yoshimoto T, Fujino T, Yada M, Yada R, Harada N et al. 2007 Re-evaluation of fatty acid metabolism-related gene expression in nonalcoholic fatty liver disease. International Journal of Molecular Medicine 20 351-358. (https://doi. org/10.3892/ijmm.20.3.351)

Kulanuwat S, Tungtrongchitr R, Billington D \& Davies IG 2015 Prevalence of plasma small dense LDL is increased in obesity in a Thai population. Lipids in Health and Disease 14 30. (https://doi.org/10.1186/s12944015-0034-1)

Liu J, Iqbal A, Raslawsky A, Browne RW, Patel MS \& Rideout TC 2016 Influence of maternal hypercholesterolemia and phytosterol intervention during gestation and lactation on dyslipidemia and hepatic lipid metabolism in offspring of Syrian golden hamsters. Molecular Nutrition and Food Research 60 2151-2160. (https://doi.org/10.1002/ mnfr.201600116)

Maeda N 2011 Development of apolipoprotein E-deficient mice. Arteriosclerosis, Thrombosis, and Vascular Biology 31 1957-1962. (https://doi.org/10.1161/ATVBAHA.110.220574)

Magalhaes A, Matias I, Palmela I, Brito MA \& Dias S 2016 LDLcholesterol increases the transcytosis of molecules through endothelial monolayers. PLOS ONE 11 e0163988. (https://doi.org/10.1371/journal. pone.0163988)

Magnussen EB, Vatten LJ, Myklestad K, Salvesen KÅ \& Romundstad PR 2011 Cardiovascular risk factors prior to conception and the length of pregnancy: population-based cohort study. American Journal of Obstetrics and Gynecology 204 526.e1-526.e8. (https://doi. org/10.1016/j.ajog.2011.02.016)

Marseille-Tremblay C, Gravel A, Lafond J \& Mounier C 2007 Effect of an enriched cholesterol diet during gestation on fatty acid synthase, HMGCoA reductase and SREBP-1/2 expressions in rabbits. Life Sciences $\mathbf{8 1}$ 772-778. (https://doi.org/10.1016/j.Ifs.2007.07.016)

Maymunah AO, Kehinde O, Abidoye G \& Oluwatosin A 2014 Hypercholesterolaemia in pregnancy as a predictor of adverse pregnancy outcome. African Health Sciences 14 967-973. (https://doi.org/10.4314/ ahs.v14i4.28)

Mendelson MM, Lyass A, O'Donnell CJ, D'Agostino Sr RB \& Levy D 2016 ASsociation of maternal prepregnancy dyslipidemia with adult offspring dyslipidemia in excess of anthropometric, lifestyle, and genetic factors in the Framingham heart study. JAMA Cardiology 1 26-35. (https://doi. org/10.1001/jamacardio.2015.0304)

Millar JS, Cromley DA, McCoy MG, Rader DJ \& JT Billheimer JT 2005 Determining hepatic triglyceride production in mice: comparison of poloxamer 407 with Triton WR-1339. Journal of Lipid Research $\mathbf{4 6}$ 2023-2028.

Montoudis A, Boileau S, Simoneau L \& Lafond J 2003 Impact of an enriched-cholesterol diet on enzymatic cholesterol metabolism during rabbit gestation. Life Sciences 73 1463-1477. (https://doi.org/10.1016/ s0024-3205(03)00436-3)
Morrison KM, Anand SS, Yusuf S, Atkinson SA, Schulze KM, Rao-Melacini P, Mcqueen MJ, Mcdonald S, Persadie R, Hunter B et al. 2013 Maternal and pregnancy related predictors of cardiometabolic traits in newborns. PLOS ONE 8 e55815. (https://doi.org/10.1371/journal.pone.0055815)

Napoli C, Glass CK, Witztum JL, Deutsch R, D'Armiento FP \& Palinski W 1999 Influence of maternal hypercholesterolaemia during pregnancy on progression of early atherosclerotic lesions in childhood: Fate of Early Lesions in Children (FELIC) study. Lancet 354 1234-1241. (https://doi. org/10.1016/S0140-6736(99)02131-5)

Narverud I, Van Lennep JR, Christensen JJ, Versmissen J, Gran JM, Iversen PO, Aukrust P, Halvorsen B, Ueland T, Ulven SM et al. 2015 Maternal inheritance does not predict cholesterol levels in children with familial hypercholesterolemia. Atherosclerosis 243 155-160. (https:// doi.org/10.1016/j.atherosclerosis.2015.09.014)

Neeland IJ, Poirier P \& Despres JP 2018 Cardiovascular and metabolic heterogeneity of obesity: clinical challenges and implications for management. Circulation 137 1391-1406. (https://doi.org/10.1161/ CIRCULATIONAHA.117.029617)

Olkkonen VM, Beaslas O \& Nissila E 2012 Oxysterols and their cellular effectors. Biomolecules 2 76-103. (https://doi.org/10.3390/ biom2010076)

Oorni K, Lehti S, Sjovall P \& Kovanen PT 2019 Triglyceride-rich lipoproteins as a source of proinflammatory lipids in the arterial wall. Current Medicinal Chemistry 26 1701-1710. (https://doi.org/10.2174/0 929867325666180530094819)

Palmer WK, Emeson EE \& Johnston TP 1998 Poloxamer 407-induced atherogenesis in the C57BL/6 mouse. Atherosclerosis 136 115-123.

Pfaffl MW 2001 A new mathematical model for relative quantification in real-time RT-PCR. Nucleic Acids Research 29 e45. (https://doi. org/10.1093/nar/29.9.e45)

Prenner SB, Mulvey CK, Ferguson JF, Rickels MR, Bhatt AB \& Reilly MP 2014 Very low density lipoprotein cholesterol associates with coronary artery calcification in type 2 diabetes beyond circulating levels of triglycerides. Atherosclerosis 236 244-250. (https://doi.org/10.1016/j. atherosclerosis.2014.07.008)

Puri P, Baillie RA, Wiest MM, Mirshahi F, Choudhury J, Cheung O, Sargeant C, Contos MJ \& Sanyal AJ 2007 A lipidomic analysis of nonalcoholic fatty liver disease. Hepatology 46 1081-1090. (https://doi. org/10.1002/hep.21763)

Rideout TC, Harding SV \& Jones PJ 2010 Consumption of plant sterols reduces plasma and hepatic triglycerides and modulates the expression of lipid regulatory genes and de novo lipogenesis in C57BL/6J mice. Molecular Nutrition and Food Research 54 (Supplement 1) S7-S13. (https://doi.org/10.1002/mnfr.201000027)

Rideout TC, Movsesian C, Tsai YT, Iqbal A, Raslawsky A \& Patel MS 2015 Maternal phytosterol supplementation during pregnancy and lactation modulates lipid and lipoprotein response in offspring of apoE-deficient mice. Journal of Nutrition 145 1728-1734. (https://doi.org/10.3945/ jn.115.215061)

Romejko-Wolniewicz E, Lewandowski Z, Zareba-Szczudlik J \& Czajkowski K 2014 BMI of the firstborn offspring at age 12 reflects maternal LDL and HDL cholesterol levels at term pregnancy and postpartum. Journal of Maternal-Fetal and Neonatal Medicine 27 914-920. (https://doi.org/10.3109/14767058.2013.846314)

Rutledge JC, Mullick AE, Gardner G \& Goldberg IJ 2000 Direct visualization of lipid deposition and reverse lipid transport in a perfused artery: roles of VLDL and HDL. Circulation Research 86 768-773. (https://doi.org/10.1161/01.res.86.7.768)

Schisterman EF, Mumford SL, Browne RW, Barr DB, Chen Z \& Louis GM 2014 Lipid concentrations and couple fecundity: the LIFE study. Journal of Clinical Endocrinology and Metabolism 99 2786-2794. (https://doi. org/10.1210/jc.2013-3936)

Sim WC, Park S, Lee KY, Je YT, Yin HQ, Choi YJ, Sung SH, Park SJ, Park HJ, Shin KJ et al. 2014 LXR-alpha antagonist meso-dihydroguaiaretic acid attenuates high-fat diet-induced nonalcoholic fatty liver. Biochemical Pharmacology 90 414-424. (https://doi.org/10.1016/j. bcp.2014.06.013)

Stahlberg D, Rudling M, Angelin B, Bjorkhem I, Forsell P, Nilsell K \& Einarsson K 1997 Hepatic cholesterol metabolism in human obesity. Hepatology 25 1447-1450. (https://doi.org/10.1002/hep.510250623)

Tonstad S, Joakimsen O, Leren TP \& Ose L 2000 Does maternal or paternal heredity affect carotid atherosclerosis in children with familial 
hypercholesterolaemia? Acta Paediatrica 89 1490-1492. (https://doi. org/10.1080/080352500456705)

Tsuduki T, Yamamoto K, Hatakeyama Y \& Sakamoto Y 2016 High dietary cholesterol intake during lactation promotes development of fatty liver in offspring of mice. Molecular Nutrition and Food Research $\mathbf{6 0}$ 1110-1117. (https://doi.org/10.1002/mnfr.201500736)

Van Der Graaf A, Vissers MN, Gaudet D, Brisson D, Sivapalaratnam S, Roseboom TJ, Jansen AC, Kastelein JJ \& Hutten BA 2010 Dyslipidemia of mothers with familial hypercholesterolemia deteriorates lipids in adult offspring. Arteriosclerosis, Thrombosis, and Vascular Biology $\mathbf{3 0}$ 2673-2677. (https://doi.org/10.1161/ATVBAHA.110.209064)

Vasile E, Antohe F, Simionescu M \& Simionescu N 1989 Transport pathways of beta-VLDL by aortic endothelium of normal and hypercholesterolemic rabbits. Atherosclerosis 75 195-210. (https://doi.org/10.1016/00219150(89)90177-9)

Versmissen J, Botden IP, Huijgen R, Oosterveer DM, Defesche JC, Heil TC, Muntz A, Langendonk JG, Schinkel AF, Kastelein JJ et al. 2011 Maternal inheritance of familial hypercholesterolemia caused by the V408M low-density lipoprotein receptor mutation increases mortality. Atherosclerosis 219 690-693. (https://doi.org/10.1016/j. atherosclerosis.2011.08.039)

Vrins CL, Out R, Van Santbrink P, Van Der Zee A, Mahmoudi T, Groenendijk M, Havekes LM, Van Berkel TJ, Willems Van Dijk K \& Biessen EA 2013 Znf202 affects high density lipoprotein cholesterol levels and promotes hepatosteatosis in hyperlipidemic mice. PLOS ONE 8 e57492. (https://doi.org/10.1371/journal.pone.0057492)

Yamazaki T, Sasaki E, Kakinuma C, Yano T, Miura S \& Ezaki O 2005 Increased very low density lipoprotein secretion and gonadal fat mass in mice overexpressing liver DGAT1. Journal of Biological Chemistry 280 21506-21514. (https://doi.org/10.1074/jbc.M412989200)

Zhou Y, Zhang X, Chen L, Wu J, Dang H, Wei M, Fan Y, Zhang Y, Zhu Y, Wang N et al. 2008 Expression profiling of hepatic genes associated with lipid metabolism in nephrotic rats. American Journal of Physiology: Renal Physiology 295 F662-F671. (https://doi.org/10.1152/ ajprenal.00046.2008)

Zhou Y, Robciuc MR, Wabitsch M, Juuti A, Leivonen M, Ehnholm C, YkiJarvinen H \& Olkkonen VM 2012 OSBP-related proteins (ORPs) in human adipose depots and cultured adipocytes: evidence for impacts on the adipocyte phenotype. PLOS ONE 7 e45352. (https://doi.org/10.1371/ journal.pone.0045352)

Received 4 February 2020

First decision 21 February 2020

Revised manuscript received 1 April 2020

Accepted 9 April 2020 